\title{
BMJ Open Patient or family perceived deterioration in functional status and outcome after intensive care admission: a retrospective cohort analysis of routinely collected data
}

\author{
Jamie L Gross (D) , ${ }^{1,2}$ Jacek Borkowski (D) , ${ }^{1}$ Stephen J Brett (iD) ${ }^{2}$
}

To cite: Gross JL, Borkowski J, Brett SJ. Patient or family perceived deterioration in functional status and outcome after intensive care admission: a retrospective cohort analysis of routinely collected data. BMJ Open 2020;10:e039416. doi:10.1136/ bmjopen-2020-039416

- Prepublication history for this paper is available online. To view these files, please visit the journal online (http://dx.doi. org/10.1136/bmjopen-2020039416).

Received 16 April 2020 Revised 20 July 2020 Accepted 25 August 2020
A) Check for updates

(C) Author(s) (or their employer(s)) 2020. Re-use permitted under CC BY-NC. No commercial re-use. See rights and permissions. Published by BMJ.

${ }^{1}$ Anaesthetics and Intensive Care, London North West University Healthcare NHS Trust, Harrow, UK

${ }^{2}$ Anaesthetics, Pain Medicine and Intensive Care, Department of Surgery and Cancer, Imperial College London, London, UK

Correspondence to

Dr Jamie L Gross;

j.gross@imperial.ac.uk

\section{ABSTRACT}

Objective To explore the association of patient or family reported functional deterioration (defined by a single question) in the preceding year, with mortality outcome for those admitted to the intensive care unit (ICU).

Design Retrospective observational analysis of a routinely collected data source.

Participants Patients that were admitted to the ICU at Northwick Park and St Marks Hospitals, London North West University Healthcare NHS Trust between 01 October 2017 to 15 June 2019 were included. Patients were excluded if they had a prior ICU admission during the existing hospital episode or if information on functional deterioration could not be retrieved from either the patient or their advocate.

Primary outcomes Mortality at the point of hospital discharge and 1 year following admission to the ICU. Results Of the 1006 patients who were admitted to the ICU during the study period, information on functional deterioration was available for 621 patients who were included in the analysis. From these, 251 (40.4\%) patients had patient or family reported functional deterioration in the preceding year, while $370(59.6 \%)$ patients had a perceived stable functional baseline. Comparing the two groups, mortality was significantly higher in those who had functionally deteriorated compared with those with stable baseline function, at the point of hospital discharge $(45.4 \%$ vs $25.9 \% ; p<0.0001)$ and at 1 year $(59.4 \%$ vs $33.0 \%$; $\mathrm{p}<0.0001)$.

\section{Conclusion Patient or family reported functional} deterioration was significantly associated with higher mortality at the point of hospital discharge and at 1 year. The concept of functional deterioration in the lead up to ICU admission warrants further exploration.

\section{INTRODUCTION}

Although life-saving for many patients, approximately $20 \%$ of all those admitted to the intensive care unit (ICU) don't survive. ${ }^{1}$ A prolonged stay in ICU may be unpleasant and distressing to patients and families and in the longer-term, physical, psychological and social morbidity are well described. ${ }^{2-6}$ This may translate to a poor quality of life
Strengths and limitations of this study

- This is the first known UK study to explore the concept of a change in physical status and how it might relate to outcomes for patients admitted to the intensive care unit.

- A 'yes-no' question that explores this phenomenon offers the potential for easier transferability into clinical settings (subject to further research).

- This study involved the retrospective analysis of a routine data-source in a single-centre setting.

- Treating clinicians were unblinded to this concept of functional deterioration, which may have subtly altered end-of-life decision-making.

for survivors. ${ }^{78}$ Therefore, a greater understanding of which patients may benefit from admission to the ICU is crucial, and has been identified as a research priority. ${ }^{9}$ Outcome prediction scoring systems (eg, Acute Physiology and Chronic Health Evaluation (APACHE) II, ${ }^{10}$ Intensive Care National Audit Research Centre ${ }^{11}$ (ICNARC) score) are used to calculate expected mortality outcomes thereby allowing individual ICUs to benchmark their performance against other units. $^{12}$ Although weighted towards acute physiological derangement, scoring systems may also incorporate non-physiological parameters, which include age, comorbidity, frailty and emergency indication for ICU admission. However, the concept of decline in functional status and worsening trajectory is not included, despite it being described in the medical literature for over a decade in patients that are towards end of life, ${ }^{13}$ in certain chronic disease states ${ }^{14}$ and those who are frail. $^{15}$

As part of continuing service evaluation and quality improvement, we explored the association of patient-reported or family-reported 
deterioration in functional status prior to ICU and hospital admission with subsequent mortality and survivors discharge destination.

\section{METHODS}

\section{Study setting}

The study was performed on a 22-bedded ICU which serves a busy district general hospital (Northwick Park) and a tertiary hospital specialising in colorectal diseases (St Marks). These hospitals form part of the London North West University Healthcare NHS Trust-an organisation which has two additional hospitals on other sites and has 1037 acute hospital beds in total.

\section{Study design}

A retrospective cohort observational analysis of routinely collected data comparing patients admitted to the ICU who had self-reported or family-reported functional deterioration in the previous year compared with patients whose prior functional status was perceived as stable.

\section{Patients and data source}

Institutional approval was granted on the basis that this project was a service evaluation using routinely collected de-identified data; formal ethical approval and informed consent was not deemed to be necessary under prevailing National Health Service (NHS) regulations.

Data were collected at the point of ICU admission for all those admitted between $1^{\text {st }}$ October 2017 and $15^{\text {th }}$ June 2018 at Northwick Park Hospital ICU, London North West University Healthcare NHS Trust, London UK. Patients were excluded if they had a prior admission to the ICU during the current hospital stay. Data that are routinely collected for the ICNARC case mix programme (CMP) were recorded on observational charts, in the medical records and hospital information systems. In addition to the routine CMP data, information was collected on frailty status defined by the Rockwood Clinical Frailty Scale (RCFS) ${ }^{16}$ and patient or family reported worsening functional status in the preceding year (dichotomised into yes/no categories).

Information on mortality outcome 1 year following hospital discharge was introduced 6 months prior as part of routine and data collection for the purposes of ongoing service evaluation. This was ascertained using the NHS spine portal system-a NHS web-based platform containing a summary of clinical patient information including date of death where applicable. Access was previously granted for service evaluation purposes. Survival status at exactly 1 year following ICU admission was collected, along with discharge destination. This marked the end of the patient follow-up period (ie, patient survival status was not collected beyond 1 year). At the time of data analysis, all data were de-identified.

\section{Patient and public involvement}

As this was a service evaluation exercise involving the analysis of routinely collected data, patients were not directly involved in the design of this study. However, the latest research prioritisation exercise for UK Intensive Care had strong patient and public representation (James-Lind Alliance Priority Setting Partnership). ${ }^{9}$ This highlighted the need to better define which patients are more and less likely to benefit from an admission to the ICU as one of the most important priorities for UK Intensive Care research.

\section{Outcome measures and statistical analysis}

Patient data were dichotomised into two groups-those with and without prior functional deterioration. Primary outcome measures were survival status at the point of hospital discharge and survival status at 1 year following ICU admission. Secondary outcome was the discharge destination for hospital survivors. Data are presented as mean with $\mathrm{SD}$ or median with IQR for parametric and non-parametric data, respectively. Kaplan-Meier survival curves were constructed and the two groups were compared using the log-rank and $\chi^{2}$ tests of mortality at hospital discharge and at 1 year calculated for each group. Categorical variables were compared using the $\chi^{2}$ or Fisher's exact test.

\section{RESULTS}

During the study period from 01 October 2017 to 15 June 2018, 1006 patients were admitted to our ICU. Two hundred and seventy-eight patients were excluded due to incomplete data and a further 107 patients were excluded as they were ICU readmissions. After exclusions, 621 patients further analysed. Table 1 presents baseline characteristic of studied groups.

From all patients that were analysed, $40.4 \%$ had self or family reported functional deterioration in the preceding year. These patients were older (mean age 67.4 vs 59.9 years), had proportionally more severe comorbidities in their past medical history (as defined by the CMP; $66.9 \%$ vs $55.4 \%$ ), had significantly higher frailty scores (median (IQR) RCFS 5 (4 to 5) vs RCFS 3 (2 to 3); p<0.0001) and higher acute illness severity scores at the point of ICU admission. There were also a higher proportion of nonsurgical and emergency ICU admissions for those who had reported functional deterioration compared with those who did not.

Although the patients who were admitted had a median of two organ failures in each group, those who had a prior stable baseline function more commonly received advanced respiratory support $(61.4 \%$ vs $51.2 \%$; $=0.0181)$, while those with a prior worsening functional status more commonly received renal replacement therapy $(42.6 \%$ vs $24.9 \% ; \mathrm{p}<0.0001)$. Withdrawal of organ support was more common in those with a prior worsening functional status and occurred in $15.1 \%$ of these patients (table 2 ). 
Table 1 Baseline patient characteristics

\begin{tabular}{|c|c|c|c|}
\hline & $\begin{array}{l}\text { Functional } \\
\text { deterioration }\end{array}$ & $\begin{array}{l}\text { Stable baseline } \\
\text { function }\end{array}$ & P values \\
\hline Number of patients & $251(40.4 \%)$ & $370(59.6 \%)$ & $p=0.0001$ \\
\hline Male & $146(40.2 \%)$ & $217(59.8 \%)$ & $p=0.0023$ \\
\hline Female & $105(40.7 \%)$ & $153(59.3 \%)$ & $\mathrm{p}=0.0147$ \\
\hline SOFA score ${ }^{28}$ (median) (IQR) & $7.0(5-8)$ & $6.0(4-8)$ & $p=0.0285$ \\
\hline Severe comorbidities in past medical history & $168(66.9 \%)$ & $205(55.4 \%)$ & $\mathrm{p}=0.0040$ \\
\hline Severe liver disease & $4(1.6 \%)$ & $4(1.1 \%)$ & $p=0.5813$ \\
\hline Severe respiratory disease or home ventilation & $55(22.0 \%)$ & $68(18.4 \%)$ & $\mathrm{p}=0.2677$ \\
\hline \multicolumn{4}{|l|}{ Prior residence before ICU admission } \\
\hline Nursing home & $7(2.9 \%)$ & $5(1.4 \%)$ & $\mathrm{p}=0.2083$ \\
\hline Healthcare institution & $1(0.4 \%)$ & $2(0.5 \%)$ & $p=0.8556$ \\
\hline Rockwood Clinical Frailty Score ${ }^{16}$ (median) (IQR) & $5.0(4-5)$ & $3.0(2-3)$ & $p<0.0001$ \\
\hline Emergency admission & $230(91.6 \%)$ & $310(83.4 \%)$ & $p=0.0044$ \\
\hline $\begin{array}{l}\text { Cardiopulmonary resuscitation within } 24 \text { hours prior to } \\
\text { admission }\end{array}$ & $17(6.8 \%)$ & $32(8.6 \%)$ & $p=0.3952$ \\
\hline Non-surgical admissions & $192(76.4 \%)$ & $234(63.2 \%)$ & $p=0.1347$ \\
\hline Surgical admissions & $59(23.5 \%)$ & $136(36.8 \%)$ & $p=0.0108$ \\
\hline Prior hospital admission in last year & $165(66.0 \%)$ & 185 (50.4\%) & $\mathrm{p}=0.0456$ \\
\hline
\end{tabular}

Percentages stated for number of patients, male/female refer to row totals; other percentages stated refer to column totals; numbers in superscript represent references.

APACHE II, Acute Physiology and Chronic Health Evaluation II; ICNARC, Intensive Care National Audit Research Centre; ICU, intensive care unit; SOFA, Sequential Organ Failure Assessment.

Survival rates were significantly lower for patients who had a worsening functional status when compared with those with stable baseline function at the point of ICU and hospital discharge and at 1 year (table 3; figure 1 ). At 1 year, overall mortality rates were $59.4 \%$ and $33.0 \%$ for patients who had a worsening functional and stable baseline, respectively $(\mathrm{p}<0.0001)$. For hospital survivors, 1-year mortality rates were $25.4 \%$ and $9.6 \%$ for patients who had a worsening functional and stable baseline, respectively $(p<0.0005)$. Sixteen per cent of patients with a prior functional deterioration (compared with $10.6 \%$ of patients with prior stable baseline function) did not return to their preadmission residence $(\mathrm{p}=0.0812)$.

\section{DISCUSSION}

In this study, a simple question that asks whether or not patients had any deterioration in their functional

Table 2 Treatment on ICU by worsening or stable functional status prior to ICU admission

\begin{tabular}{|c|c|c|c|}
\hline & Functional Deterioration & Stable baseline function & $\mathrm{X}^{2} \mathrm{P}$ value \\
\hline Advanced respiratory support & $130(51.8 \%)$ & $227(61.4 \%)$ & $p=0.0181$ \\
\hline Renal replacement therapy & $107(42.6 \%)$ & $92(24.9 \%)$ & $p<0.0001$ \\
\hline Active treatment withdrawn & $38(15.1 \%)$ & $40(10.8 \%)$ & $p=0.1105$ \\
\hline
\end{tabular}

All percentages stated refer to column totals.

ICU, intensive care unit. 
Table 3 Clinical outcomes by trajectory status

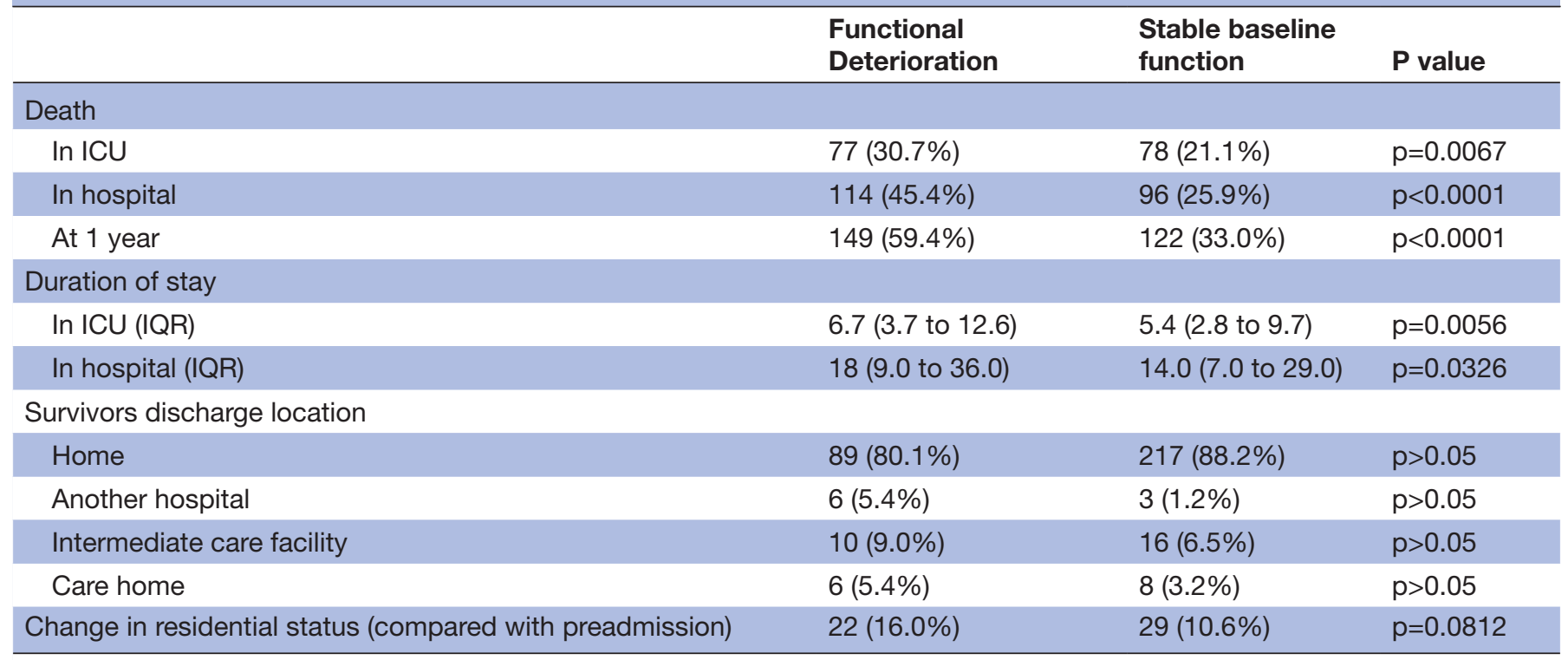

All percentages stated refer to column totals.

ICU, intensive care unit.

status within the year preceding ICU admission, showed a significant association with a higher mortality. Trajectory patterns have been extensively studied in patients who are at the end of life, ${ }^{17}$ but studies looking at trajectory patterns for those admitted to the ICU are scarce. One exception is an observational analysis of the elderly admitted to the ICU in Connecticut, USA, which showed different trajectory patterns relating to changes in the number of disabilities in the 1 year prior to ICU admission. ${ }^{18}$ In this study, a worsening disability trajectory was associated with higher mortality and worse longer-term functional outcomes compared with those whose prior trajectory was stable. This could be reflective of frailty-a concept that describes an increased vulnerability to a dramatic decline in health status, often prompted by an apparent minor stressor. Frailty studies are now widely reported in the intensive care literature with consistent findings that frailty is associated worse outcomes following an ICU admission. ${ }^{19-25}$ However, most studies include only static assessments of frailty-usually at the point just prior to hospital or ICU admission. Frailty is not a static concept and longitudinal studies which have

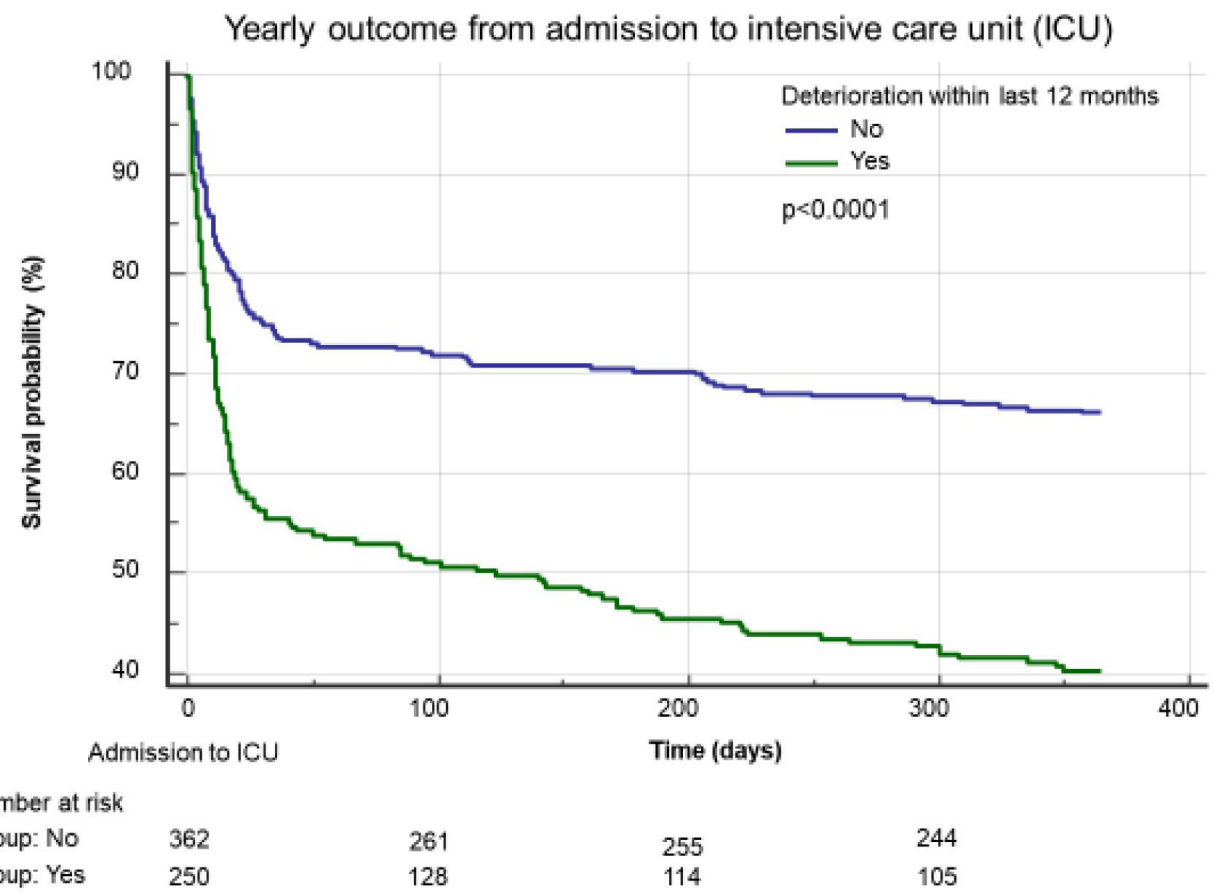

Figure 1 Kaplan-Meier survival curves of patients after 1 year from admission to the ICU. 
followed frailty over time have described different frailty trajectories in the elderly. These studies have demonstrated that those with worsening frailty trajectories are associated with lower survival. ${ }^{1526}$

In the UK, $15 \%$ to $20 \%$ of those admitted to ICU, do not survive that hospital admission and data from Wales show that one in five ICU survivors die within 1 year of discharge from hospital. ${ }^{1}$ Therefore, a significant proportion of patients that are admitted to ICUs are in the last year of life. In this current study, worsening functional status was reported in $40.4 \%$ of patients admitted to the ICU for whom information was available. Its association with a worse mortality outcome poses an important question as to whether some of these patients are already on a terminal decline, for which ICU admission is unlikely to offer benefit if the goal is sustained survival. There was a trend for surviving patients with a prior functional decline to be living less independently, although this observation did not reach statistical significance, most likely due to small numbers. In this evaluation we were not able to capture the intensity of social support needed to keep people in their homes; this should be captured in future studies.

Further research is recommended to explore further whether functional deterioration can be accurately defined by a single point question and whether it holds prognostic significance when applied to larger numbers of patients across multiple centres. The simplicity of a single question to define functional deterioration may offer opportunities to translate this into routine practice. This might include defining a cohort who are more likely to benefit from advance care planning discussions or aiding clinicians decide whether life-saving or palliative interventions are most appropriate. Although it can be argued that the association of worsening functional status to mortality outcome is unadjusted for other known prognostic variables, this might be viewed as a strength. In this study, patients that had a worsening functional status were older, had a higher acute illness severity, more severe comorbidities and higher frailty scores. It is plausible that any functional deterioration might be a representation of underlying chronic disease and frailty that culminates in diminished physiological and functional reserve to overcome the impact of critical illness resulting in poorer outcomes. This concept also warrants further exploration.

\section{Limitations}

This study was performed in a single centre over a relatively short time period, with a modest numbers of patients. Data on change in functional status were not collected for $31.0 \%$ ( $n=278$ ) of all those admitted during the study period. The responsibility of collecting this information was given to physiotherapy staff. Patients were commonly missed because the duration of ICU stay was too short to be fully assessed by a member of the physiotherapy team. The rationale for using the physiotherapy staff was because they regard changes in functional status as an important component in their routine clinical assessment; because this was a service evaluation exercise, it was not thought appropriate to ask other staff to deviate from routine clinical practice. Patients were also missed when it was not possible to ascertain the answer to the question-usually when patients lacked capacity and no family member was available. We did not collect data on who answered the question (patient or their relative), which will need evaluating in a future study, or whether there were any difficulties from either patient or their family in understanding the question fully. The ICU consultants were informed of the study and not intentionally blinded to the information on whether or patients had experienced any prior functional deterioration-but were not specifically informed of this. Conceivably this knowledge may have influenced decision-making relating to ICU admission and end-of-life care, even though the association of worsening functional status and mortality were unknown at the time. However, figure 1 shows that the mortality effect continues in the first year after discharge ( $25.4 \%$ vs $9.6 \%$ post discharge deaths, $\mathrm{p}<0.0001)$, during which the outcome can't be obviously influenced by in-hospital decision-making. Additionally, there was no significant difference in numbers of patients where active organ supportive treatment was withdrawn (table 2).

\section{Impact on current practice}

Since the results have been disseminated locally, it has been emphasised to healthcare professionals that findings demonstrating a higher mortality association in patients with a worsening functional status should be used for the purpose of hypothesis generation until further welldesigned studies are conducted. Worsening functional status should not dominate decisions as to whether a patient is or is not admitted to the ICU. However, owing to the fact that some of these patients might not have favourable outcomes from ICU admission, its current use might be suitable for the purpose of increasing patient (and family) involvement in treatment escalation planning and where appropriate, ceilings of care. It is now well understood that any patient admitted to the ICU is at risk of ICU-related physical ${ }^{25}$ and psychosocial morbidity. ${ }^{4}$ In nsituations where a preferred outcome is less likely or uncertain, it may be difficult to obtain a multi-professional consensus on the best interests of the patient (ie, should they be admitted?). In such situations, patient and family involvement in the decision-making process is highly desirable. ${ }^{27}$ Therefore, worsening functional deterioration could be used (along with other patient characteristics) to highlight individuals earlier in their hospital stay that may benefit from discussions relating to treatment escalation planning and ceilings of care where appropriate. This information has been disseminated across our institution. 


\section{CONCLUSION}

In this study, patient or family reported functional deterioration occurring in the 1 year preceding ICU admission was associated with a significant increased incidence of in-hospital mortality. This remained significant 1 year later. Owing to a number of limitations including small sample size in a single centre, further studies are recommended in wider settings to explore this concept further.

Twitter Jamie L Gross @GrossJamie

Acknowledgements Infrastructure support was provided by the NIHR Imperial BRC. The views expressed are those of the authors and not necessarily those of NIHR, the NHS or the UK Department of Health and Social Care.

Contributors Concept and design of study: JG, SB. Collection and curation of data: JB. Analysis: JB. Interpretation: JG, JB, SB. Drafting manuscript: JG, SB. Revising manuscript for important intellectual content: JG, JB, SB. All authors have seen and approve of the final submitted version.

Funding The authors have not declared a specific grant for this research from any funding agency in the public, commercial or not-for-profit sectors.

\section{Competing interests None declared.}

Patient and public involvement Patients and/or the public were not involved in the design, or conduct, or reporting, or dissemination plans of this research.

Patient consent for publication Not required.

Provenance and peer review Not commissioned; externally peer reviewed.

Data availability statement Data are available in a public, open access repository. Technical appendix, statistical code and data set will be submitted to and made available by the Dryad repository on request. Extra data can be accessed via the Dryad data repository at http://datadryad.org/ with the doi: 10.5061/dryad. qnk98sfcv.

Open access This is an open access article distributed in accordance with the Creative Commons Attribution Non Commercial (CC BY-NC 4.0) license, which permits others to distribute, remix, adapt, build upon this work non-commercially, and license their derivative works on different terms, provided the original work is properly cited, appropriate credit is given, any changes made indicated, and the use is non-commercial. See: http://creativecommons.org/licenses/by-nc/4.0/.

\section{ORCID iDs}

Jamie L Gross http://orcid.org/0000-0001-7219-8173

Jacek Borkowski http://orcid.org/0000-0003-4686-9767

Stephen J Brett http://orcid.org/0000-0003-4545-8413

\section{REFERENCES}

1 Faculty of Intensive Care Medicine. Care at the end of life: a guide to best practice, discussion and decision making in and around critical care, 2019. Available: https://www.ficm.ac.uk/sites/default/files/ficm care_end_of_life_0.pdf

2 Iwashyna TJ, Ely EW, Smith DM, et al. Long-term cognitive impairment and functional disability among survivors of severe sepsis. JAMA 2010;304:1787.

3 Reade MC, Finfer S. Sedation and delirium in the intensive care unit - NEJM. N Engl J Med 2014

4 Wade DM, Brewin CR, Howell DCJ, et al. Intrusive memories of hallucinations and delusions in traumatized intensive care patients: an interview study. Br J Health Psychol 2015;20:613-31.
5 Herridge MS. Legacy of intensive care unit-acquired weakness. Crit Care Med 2009;37:S457-61.

6 Sukantarat K, Brett SJ. The neuropsychological consequences of intensive care. Surviv Intensive Care Updat Intensive Care Med 2003;39:51-61.

7 Cuthbertson BH, Roughton S, Jenkinson D, et al. Quality of life in the five years after intensive care: a cohort study. Crit Care 2010;14:R6.

8 Oeyen SG, Vandijck DM, Benoit DD, et al. Quality of life after intensive care: a systematic review of the literature. Crit Care Med 2010;38:2386-400.

9 Reay H, Arulkumaran N, Brett SJ. Priorities for future intensive care research in the UK: results of a James Lind alliance priority setting partnership. J Intensive Care Soc 2014.

10 Knaus WA, Draper EA, Wagner DP, et al. Apache II: a severity of disease classification system. Crit Care Med 1985;13:818-29.

11 Ferrando-Vivas P, Jones A, Rowan KM, et al. Development and validation of the new ICNARC model for prediction of acute hospital mortality in adult critical care. J Crit Care 2017;38:335-9.

12 Desai N, Gross J. Scoring systems in the critically ill: uses, cautions, and future directions. BJA Education 2019;19:212-8.

13 Murray SA, Kendall M, Boyd K, et al. Illness trajectories and palliative care. BMJ 2005;330:1007-11.

14 Pinaire J, Azé J, Bringay S, et al. Patient healthcare trajectory. an essential monitoring tool: a systematic review. Health Inf Sci Syst 2017;5:1.

15 Stow D, Matthews FE, Hanratty B. Frailty trajectories to identify end of life: a longitudinal population-based study. BMC Med 2018; $16: 171$

16 Rockwood K, Song X, MacKnight C, et al. A global clinical measure of fitness and frailty in elderly people. CMAJ 2005;173:489-95.

17 Cohen-Mansfield J, Skornick-Bouchbinder M, Brill S. Trajectories of end of life: a systematic review. J Gerontol B Psychol Sci Soc Sci 2018;73:564-72.

18 Ferrante LE, Pisani MA, Murphy TE, et al. Functional trajectories among older persons before and after critical illness. JAMA Intern Med 2015;175:523.

19 Muscedere J, Waters B, Varambally A, et al. The impact of frailty on intensive care unit outcomes: a systematic review and meta-analysis. Intensive Care Med 2017:43:1105-22.

20 Brummel NE, Bell SP, Girard TD, et al. Frailty and subsequent disability and mortality among patients with critical illness. Am J Respir Crit Care Med 2017;196:64-72.

21 Bagshaw SM, Stelfox HT, Johnson JA, et al. Long-Term association between frailty and health-related quality of life among survivors of critical illness: a prospective multicenter cohort study. Crit Care Med 2015;43:973-82.

22 Flaatten $\mathrm{H}$, De Lange DW, Morandi $\mathrm{A}$, et al. The impact of frailty on ICU and 30-day mortality and the level of care in very elderly patients ( $\geq 80$ years). Intensive Care Med 2017;43:1820-8.

23 Hewitt D, Booth MG. The FRAIL-FIT study: frailty's relationship with adverse-event incidence in the longer term, at one year following intensive care unit treatment - a retrospective observational cohort study. J Intensive Care Soc 2019:175114371983821.

24 Le Maguet P, Roquilly A, Lasocki S, et al. Prevalence and impact of frailty on mortality in elderly ICU patients: a prospective, multicenter, observational study. Intensive Care Med 2014;40:674-82.

25 Zampieri FG, Iwashyna TJ, Viglianti EM, et al. Association of frailty with short-term outcomes, organ support and resource use in critically ill patients. Intensive Care Med 2018;44:1512-20.

26 Chamberlain AM, Rutten LJF, Manemann SM, et al. Frailty trajectories in an elderly population-based cohort. J Am Geriatr Soc 2016.

27 Bassford C, Griffiths F, Svantesson M, et al. Developing an intervention around referral and admissions to intensive care: a mixed-methods study. Health Serv Deliv Res 2019;7:1-284.

28 Vincent J-L, Moreno R, Takala J, et al. The SOFA (sepsis-related organ failure assessment) score to describe organ dysfunction/ failure. Intensive Care Med 1996;22:707-10. 